\title{
Profile of levodopa/carbidopa intestinal gel and its potential in the treatment of advanced Parkinson's disease
}

This article was published in the following Dove Press journal:

Journal of Parkinsonism and Restless Legs Syndrome

2 May 2014

Number of times this article has been viewed

\author{
Sabine Skodda \\ Department of Neurology, \\ Knappschaftskrankenhaus, \\ Ruhr-University of Bochum, \\ Bochum, Germany
}

Correspondence: Sabine Skodda Department of Neurology, Knappschaftskrankenhaus, Ruhr-University of Bochum, In der Schornau 23-25, Bochum D-44892, Germany Tel +492342993704 Fax +492342993719

Email sabine.skodda@kk-bochum.de, sabine@skodda.de
Abstract: Parkinson's disease (PD) is characterized by a progression of symptoms in the course of time which typically leads to the occurrence of motor complications in the advanced stages of disease. In this stage of "motor complication", conventional oral polypharmacotherapy often fails to preserve sufficiently stable motor function during the course of the day. Continuous infusions of levodopa/carbidopa gel (LCIG) delivered directly into the small intestine by a portable pump have been shown to stabilize levodopa plasma levels and to ameliorate motor fluctuations and troublesome dyskinesias in patients in the advanced stages of PD. Furthermore, there are also some first indications for beneficial effects on dopamine-related nonmotor symptoms of PD and an amelioration of overall quality of life. On the other hand, LCIG is an elaborate and expensive therapy, which requires the assured access to a medical team who are experienced with the management of adverse events and technical problems related to the tube and pump delivery system. This review focuses on the principle of LCIG infusion therapy and gives a comprehensive summary of the existing data on therapeutic effects and adverse events and possible complications.

Keywords: motor complications, continuous dopaminergic stimulation, dyskinesia, nonmotor symptoms, quality of life

\section{Introduction}

\section{Motor fluctuations: phenomenology}

Dopamine replacement therapy with orally administered levodopa has been the mainstay of medical treatment for Parkinson's disease (PD) since its first introduction in the 1960 s. ${ }^{1}$ Levodopa has been found to typically alleviate the core motor symptoms of $\mathrm{PD}$, and responsiveness to levodopa is one of the diagnostic criteria for the presence of idiopathic PD. ${ }^{2,3}$ Unfortunately, in the course of disease progression, the majority of patients with PD develop motor complications which indicate a narrowing of the therapeutic window of levodopa and lead to major distress and functional disability for patients. ${ }^{4,5}$ Motor fluctuations often become first noticeable as "end of dose" or "wearing off" phenomena with a reemergence of parkinsonian symptoms some time period before the regular intake of the next levodopa dosage. ${ }^{6}$ Additionally, delayed "on" or "no on" (subjective absence of amelioration of PD symptoms after intake of levodopa) phenomena after intake of medication can occur (often as a consequence of reduced bioavailability of levodopa after a protein-rich meal), and sometimes "off" episodes emerge even unpredictably, which is an important contributor to functional impairment in patients with advancing PD. ${ }^{7,8}$ On the other hand, peak dose dyskinesia at the highest level of levodopa can emerge as a dysfunctional "on" period and typically consist of stereotypical choreic or ballistic movements involving the head, trunk, and 
limbs, and occasionally, the respiratory muscles. ${ }^{6}$ Complex motor fluctuations can also present as biphasic dyskinesia and additional dystonia at the transitions from higher and lower levodopa plasma levels. Furthermore, nonmotor fluctuations can lead to additional distress since they often manifest as "nonmotor off phenomena" with severe anxiety, restlessness, depressive mood, and vegetative symptoms. ${ }^{9}$ Since motor and nonmotor "off" episodes are the biggest contributor to functional impairment in patients, the ability to reduce "off" time without increasing the periods with dyskinesias is one important goal in the therapeutic management of patients with advanced PD.

\section{Motor fluctuations: mechanisms}

The mechanisms of levodopa-associated fluctuations are not fully understood, but from a simplified point of view, they seem to mirror the inability to provide physiologic continuous dopaminergic stimulation in the advanced stages of PD. ${ }^{1,10,11}$ It is thought that in the early stages of PD, a sufficient number of dopaminergic neurons in the substantia nigra still remains to store exogenously provided levodopa and metabolize and release it in a quasiphysiological way. ${ }^{12}$ However, with progressive loss of dopaminergic neurons during the course of neurodegeneration, this buffer function declines. Exogenous levodopa supplied in various portions over the blood flow is processed immediately in nondopaminergic brain structures and released without buffering. This leads to a pulsatile dopaminergic stimulation, which is increasingly dependent on the plasma level of levodopa. ${ }^{1,10,12,13}$ As a consequence, one therapeutic approach for the attenuation of fluctuations could be to keep the plasma level of levodopa as stable as possible. Unfortunately, peripheral factors such as delayed gastric emptying, reduced gastrointestinal motility, and competition of levodopa with dietary protein additionally hamper the predictability of the absorption of orally administered levodopa, which antagonizes the therapeutic approach to smooth undulations of levodopa plasma levels. ${ }^{14,15}$

\section{Motor fluctuations: conventional therapeutic strategies}

Conventional therapeutic strategies to alleviate motor and nonmotor fluctuations by providing continuous dopaminergic receptor stimulation are aimed to stabilize plasma levels of dopaminergic medication. Besides increasing the frequency/reducing the single dosage of levodopa intake, the blocking of levodopa degradation by comedication with catechol-O-methyltransferase and/or monoamine oxidase $\mathrm{B}$ inhibitors are possible ways to extend the half-life of levodopa. ${ }^{16}$ Furthermore, the goal of continuous dopaminergic stimulation can be fulfilled by the administration of dopamine receptor agonists, which have a longer half-life than levodopa and have been shown to delay the emergence of motor fluctuations when used as monotherapy in the early stages of PD. ${ }^{17,18}$ However, the use of dopamine agonists is often limited by a higher rate of disabling, adverse effects and by the insufficient effect to control motor symptoms in the more advanced stages of $\mathrm{PD}$, which therefore typically requires the combination with levodopa.

As a consequence, all these therapeutic options often require the combination of an increasing number of different medications with pill intake time schedules of rising complexity, which is often not practicable in everyday life and, nonetheless, often fail to relevantly improve motor fluctuations in the individual patients. Therefore, "escalating" therapeutic approaches for the attainment of continuous dopaminergic receptor stimulation have been developed, especially for patients who are not eligible for deep brain stimulation (DBS) for whatever reasons.

\section{Motor fluctuations: continuous parenteral drug administration}

One of these approaches consists of the continuous subcutaneous infusion of dopamine agonists to achieve stable drug plasma levels independent from gastrointestinal absorption. First experiences with continuous infusions of lisuride in PD patients with motor fluctuations led to promising results, but this approach was not established for routine application and had been abandoned over the years. ${ }^{19,20}$ Thus, the principal feasibility of continuous subcutaneous infusion of a dopamine agonist, delivered by a portable syringe driver, had been picked up later with the dopamine agonist apomorphine. However, the general benefit of continuous apomorphine administration is not infrequently antagonized by side effects (especially drug-induced psychosis) since effective monotherapy requires high doses which may be poorly tolerated. ${ }^{21-23}$ Therefore, a large subpopulation of PD patients has to take supplemental levodopa, thus undermining the principle of continuous dopaminergic drug administration. $^{22,24}$

First studies with parenteral continuous administration of levodopa were performed some decades ago and, in general, proved the concept of continuous plasma levels of levodopa leading to stable motor performance in PD. ${ }^{25,26}$ Although levodopa was found to be inapplicable for subcutaneous administration due to pharmacological 
and chemical reasons, these first experiences gave rise to the development of levodopa/carbidopa formulations for continuous gastrointestinal delivery. ${ }^{27}$

\section{Continuous intestinal levodopa/carbidopa infusion Principle of levodopa/carbidopa intestinal gel}

Levodopa/carbidopa intestinal gel (LCIG) is a carboxymethylcellulose aqueous gel consisting of $20 \mathrm{mg} / \mathrm{mL}$ levodopa and $5 \mathrm{mg} / \mathrm{mL}$ carbidopa. LCIG is delivered directly into the proximal jejunum, the place of levodopa absorption. The first step in the implementation of LCIG in patients with advanced PD and motor complications usually consists of the temporary application of a nasointestinal tube to test the clinical response. For long-term therapy, a permanent small tube has to be placed by a percutaneous endoscopic gastrostomy (PEG) beyond the pylorus in the lower duodenum/proximal jejunum. The LCIG is supplied in cassettes with $100 \mathrm{~mL}$ each and is administered by a portable pump, which can be carried by the patient in a bag or other special strap-on devices. LCIG is usually infused continuously through the daytime hours and stopped at night; however, some patients also benefit from 24-hour treatment, which especially can lead to an improvement of Parkinson-induced sleep disturbance. The approximate dosage of LCIG can be calculated based upon the previous oral levodopa equivalence dosage and titrated stepwise according to the patient's needs. Typically, an individual morning bolus dosage is used to rapidly achieve an "on" condition; and bolus dosages can be used over the course of the day in addition to the continuous infusion rate to cope with eventual "off" episodes.

\section{Pharmacokinetics}

In the rat model, intestinal levodopa infusions have been shown to achieve stable levodopa plasma levels in contrast to pulsatile administration. ${ }^{28,29}$ First experience with intestinal levodopa infusions in patients with advanced PD was reported by Kurlan et al and was later pursued by other groups who were able to demonstrate that direct duodenal levodopa infusions were possible and led to a smoothening of motor fluctuations. ${ }^{30-33}$ Similar results were found in an early clinical study with five patients with advanced PD, where levodopa plasma levels varied significantly under oral therapy but remained stable with continuous duodenal infusions of levodopa. ${ }^{34}$ However, one limitation of those first approaches of direct intestinal levodopa infusions was the requirement of very large infusion volumes impeding its clinical practicability. After improvement of the levodopa preparations rendering smaller infusion volumes on the gel basis, the initial promising findings could be reproduced in subsequent trials with six to ten patients where the minimal levodopa plasma levels were significantly lower under LCIG infusions than with oral levodopa administration. ${ }^{35-37}$ From the clinical point of view, "on" time and dyskinesias were improved in the majority of participants compared to the baseline condition, which seemed to confirm the hypothesis that motor fluctuations are related to varying levodopa plasma levels. ${ }^{35-37}$ LCIG infusions have also shown to be superior to oral therapy with controlled-release levodopa medication (and additional instant-release levodopa when needed) in a crossover 6-weeks trial in 12 patients with advanced PD. The variation of mean ranges of plasma levodopa levels was significantly lower with LCIG infusions. ${ }^{38}$ A recent investigation performed in 19 patients under continuous LCIG infusion therapy for at least 30 days reproduced the previous findings of only very low fluctuations of levodopa plasma concentrations. ${ }^{39}$

\section{Efficacy and tolerability of LCIG Treatment of motor fluctuations}

Table 1 summarizes the findings of LCIG infusion therapy studies. LCIG infusions had been shown to be successful in providing stable levodopa plasma levels, going along with a stabilization of patients' motor fluctuations, at least in the early short-term open-label observational studies. Randomized controlled intervention studies (evidence class I) are difficult to conduct due to several well-known problems, eg, difficulties envisaging double-blind, placebo-controlled settings, which has been performed only once in a very recent study (discussed below). Therefore, various techniques to reduce observer bias have been used to provide for somewhat objective outcome measures in open observational studies subsequently performed on LCIG treatment.

Using video-based on-off scores, Nyholm et al performed an observer-blind, randomized cross-over study with $24 \mathrm{PD}$ patients to compare individualized oral treatment with LCIG infusion for $3+3$ weeks. There was a significant amelioration of functional "on" intervals accompanied by a decrease of "off" time and no increase of dyskinesia. These improvements were mirrored by lower unified Parkinson's disease rating scale scores and significantly improved quality of life (assessed by two different questionnaires). Adverse events were similar in both treatment strategies. ${ }^{40}$ Another investigation performed by the same group provided class II evidence for the superiority 
Table I List of studies of levodopa/carbidopa gel infusion therapy

\begin{tabular}{ll}
\hline Study & Results \\
\hline $\mathrm{n}=10$ (short-term) & Motor function: $\mathrm{n}=7$ better; $\mathrm{n}=2$ worse, $\mathrm{n}=1$ no change \\
cross-over, double-blind & Plasma levodopa levels: less variability than under oral levodopa \\
$\mathrm{n}=5$ (I $2-20$ month) & Motor function: amelioration
\end{tabular}

observational

$\mathrm{n}=9$ (short-term and follow-up

after 0.5 to 2.5 years)

open-label, observational

$\mathrm{n}=6$ (6 months)

open-label, observational

$\mathrm{n}=12$ (3+3 weeks)

randomized, cross-over

$\mathrm{n}=19$

$\mathrm{n}=24(3+3$ weeks $)$

randomized, cross-over

Motor function: improvement of fluctuations

Plasma levodopa levels: less variability than under oral levodopa reduction of levodopa

consumption possible over time

Motor function: improvement of fluctuations

Plasma levodopa levels: less variability than under oral levodopa in $n=3$

Motor function: significant improvement of fluctuations

Plasma levodopa levels: less variability than under oral levodopa ( $34 \%$ versus $14 \%, P<0.0$ I)

Low variability of plasma levels of levodopa, 3-O-methyldopa, and carbidopa under LCIG infusions 39

Motor function (blinded rater video evaluation and diary): significant improvement 40

$\mathrm{n}=28$ (a total of I,045 patient-months)

of fluctuations and improvement of UPDRS III

Quality of life: significant amelioration of PDQ39 $(P<0.0 \mathrm{I})$

retrospective, descriptive

Motor function: "All patients experienced a general improvement after the

introduction of continuous treatment"

$\mathrm{n}=56$ (a total of 216 patient-years)

open-label, observational

Similar adverse events under LCIG and oral levodopa;

$\mathrm{n}=7$ deaths unrelated to LCIG; intestinal tube problems in $69 \%$ of patients during the first year

Motor function: significant improvement of fluctuations $(P<0.01)$

$\mathrm{n}=9, \mathrm{n}=7$ completed follow-up

of several months

open-label, observational

$\mathrm{n}=22$ (up to 2 years)

open-label, observational

$\mathrm{n}=9$ (18 months)

open-label, observational

$\mathrm{n}=27$ ( 12 months)

open-label, observational, prospective

$\mathrm{n}=12$ (12 months)

open-label, observational, prospective

$\mathrm{n}=9$ I

retrospective, exploratory

$\mathrm{n}=192$ (at least 12 weeks)

interim-analysis of prospective,

open-label, 54-week trial

$\mathrm{n}=35$ versus 3 I ( 12 weeks)

randomized, controlled,

double-blind, double-dummy

$n=3$

$\mathrm{n}=13$ (maximum 12 months)

open-label, observational, prospective

$\mathrm{n}=22$ (6 months)

open-label, observational, prospective

Quality of life: significant amelioration in four PDQ39 domains $(P<0.05)$

Motor function: significant improvement of fluctuations

Quality of life: significant amelioration of PDQ39

Motor function: significant improvement of fluctuations; increase of daily "on" time $(P<0.05)$

Quality of life: significant amelioration of PDQ39, correlation to motor improvement

Motor function: significant improvement of UPDRS III $(P<0.017)$

Quality of life: tendency to amelioration of PDQ39

Motor function: improvement of motor function according to patients' diaries

Quality of life: amelioration of PDQ39

Description of patients' characteristics

"Over $90 \%$ reported an improvement in motor fluctuations, quality of life, and autonomy"

Motor function: significant improvement of fluctuations; increase of daily "on"

time by $4.6 \pm 3.5$ hours/day; any adverse event: $n=186$; serious adverse events: $n=60$

Motor function: significant improvement of daily "on" time and reduction

of troublesome dyskinesias as compared to oral levodopa $(P<0.0 \mathrm{I})$

12 patients had serious adverse events, mainly related to the gastrojejunostomy tube Amelioration of complex dyskinesias

Motor function: significant improvement of daily "off" time (reduction from a mean of $50 \% \pm 14 \%$

to $11 \% \pm 9 \%$ after 6 months and reduction of dyskinesias from a mean of $17 \% \pm 15 \%$ to $3 \% \pm 6 \%$ )

Nonmotor symptoms: amelioration of anxiety, sleep disturbances

Motor function: significant improvement of daily "on" time and reduction of troublesome

dyskinesias as compared to oral levodopa (based upon UPDRS III + IV)

Nonmotor symptoms: significant improvement in six domains (cardiovascular, sleep/fatigue,

attention/memory, gastrointestinal, urinary, miscellaneous)

Quality of life: amelioration of PDQ8

$\mathrm{n}=14$ (24 I 4 months)

open-label, observational,

retrospective

Motor function: significant improvement of dyskinesia

Nonmotor symptoms: significant improvement of depressive and psychiatric symptoms;

amelioration of sleep quality and daytime somnolence

Quality of life: improvement of patients' and caregivers quality of life only in those individual patients who showed functional improvement

$\mathrm{n}=25$ (mean of 36 months)

Motor function: significant improvement of motor complications (UPDRS IV)

open-label, observational

Quality of life: amelioration of PDQ39;

significant cognitive decline in $41 \%$ of patients over time

$\mathrm{n}=29$ (at least 24 months, fulfilled

by $n=16$ )

open-label, observational

Motor function: significant improvement of daily "on" time and reduction of dyskinesias

Nonmotor symptoms: significant improvement

Quality of life: amelioration; detection of motor and cognitive decline over time 
Table I (Continued)

\begin{tabular}{|c|c|c|}
\hline Study & Results & Ref \\
\hline $\begin{array}{l}\mathrm{n}=\mathrm{I} 4 \text { (long-term) } \\
\text { open-label, observational }\end{array}$ & $\begin{array}{l}\text { Motor function: significant improvement of daily "on" time and reduction of dyskinesias; } \\
\text { amelioration of severe nocturnal dystonic pain in } n=3 \text { patients with } 24 \text { hour treatment; } \\
\mathrm{n}=\mathrm{I} \text { with peritonitis }\end{array}$ & 64 \\
\hline $\begin{array}{l}\mathrm{n}=7 \text { with dementia ( } 6 \text { months) } \\
\text { open-label, observational, prospective }\end{array}$ & $\begin{array}{l}\text { Motor function: significant improvement of UPDRS III including axial symptoms and gait; } \\
\text { reduction of dyskinesias } \\
\text { Quality of life: no change }\end{array}$ & 75 \\
\hline $\begin{array}{l}\mathrm{n}=67 \text { (follow-up in } \mathrm{n}=37 \text {, intervals } \\
\text { different) } \\
\text { open-label, observational }\end{array}$ & $\begin{array}{l}\text { Motor function: significant improvement of motor complications (UPDRS IV); } \\
\text { patients' appraisal concerning user-friendliness and global appreciation mostly positive }\end{array}$ & 77 \\
\hline
\end{tabular}

Abbreviations: LCIG, levodopa/carbidopa gel; PDQ, Parkinson's disease quality of life score; Ref, references; UPDRS, unified Parkinson's disease rating scale.

of LCIG infusions over sustained-release orally-administered levodopa in an open label cross-over trial performed over $3+$ 3 weeks in a group of 12 PD patients. Under LCIG infusions, there was a significantly lower variation of plasma levodopa concentrations, which was accompanied by a significant increase of "on" time. ${ }^{38}$

Similarly, Nilsson et al had reported on a significant improvement of motor fluctuations under LCIG therapy when compared to the previous conventional oral pharmacotherapy in a group of $28 \mathrm{PD}$ patients, with a preserved positive effect over several (on average 4.7) years, with very little disease progress reported, and without occurrence of major complications. ${ }^{41}$ In a retrospective analysis of safety issues in 58 patients with advanced PD (with some already participating in the previously mentioned studies of the same group) who were on long-term LCIG therapy (average 3.7 years), efficacy was found to be acceptable (since almost all patients had chosen to continue LCIG treatment after the test period). However, technical problems (including intestinal tube replacements and dislocations) were reported in $69 \%$ of the patients during the first year. ${ }^{42}$ The pharmacological adverse effect profile of LCIG was similar to that observed with oral dopaminergic therapy and consisted of neuropsychiatric and autonomic symptoms, which, however, tended to decrease within the first year of follow-up, maybe due to the slight reduction of the levodopa dosage (by an average of 5\% during follow-up). ${ }^{42}$

Significant improvement of "off" period duration and time with disabling dyskinesias as well as improvement of quality of life has also been reported by Antonini et al in nine PD patients who were followed-up for several months and also in a larger group of 22 patients, with maintenance of the beneficial effects up to a 2-year follow-up. However, seven patients (of 31 participants) discontinued therapy (three for poor compliance and four for adverse events). ${ }^{43,44}$ Very similar results were reported by other groups; ${ }^{45-47}$ eg, Foltynie et al presented a group of eleven patients, who at 1-year follow-up showed significant increase of "on" time (from $32.4 \%$ to $56.2 \%$ ) and a reduction of troublesome dyskinesias (from $16.6 \%$ to $8.2 \%$ ) based upon patients' diary data, and seven out of nine patients also had a significant improvement in quality of life based upon the Parkinson's Disease Questionnaire. ${ }^{47}$

In a retrospective questionnaire-based investigation, 102 patients with advanced PD, who had received LCIG therapy between 2003 and 2007, were included to investigate their clinical characteristics and the efficacy and tolerability of the treatment ${ }^{48}$ The clinical characteristics of 91 enrolled patients consisted of high age (average age of 72.7 years), long disease duration (17 years), and advanced $\mathrm{PD}$, with gait disorders in $91 \%$, visual hallucinations in $65 \%$, and dementia in $50 \%$ of patients. LCIG infusion was the last line of therapy in almost all patients since the majority of patients previously had experienced failure or contraindications of apomorphine and neurosurgical treatments. ${ }^{48}$ In a subgroup of 66 patients under long-term treatment with LCIG, over $90 \%$ reported an improvement in motor fluctuations and quality of life. ${ }^{36}$ Not surprisingly, in the remaining patients, LCIG therapy had been terminated due to lack of efficacy $(n=6)$, side effects of psychosis $(n=2)$, and technical problems with the pump or gastrostomy $(n=9)$. As a consequence, the authors stated that LCIG seemed to be "an effective last-line therapy for motor complications in Parkinson's disease". ${ }^{48}$ Analogous conclusions were made by Fernandez et al when publishing the interim analysis of a prospective open-label international study with 192 patients with motor fluctuations in advanced PD patients who were on LCIG infusion therapy for at least 12 months. Baseline mean "off" time was 6.7 hours per day and showed significant decrease by an average of 3.9 hours per day, while "on" time without severe dyskinesias was significantly improved at week 12 compared to baseline. However, 168 (87.5\%) patients reported adverse events, mainly abdominal pain 
(30.7\%), complication of device insertion (12.5\%); serious adverse events were observed in 60 patients (31.3\%); 24 patients discontinued the therapy. ${ }^{49}$

A very recent randomized, double-blind double-dummy multicenter study over 12 weeks which allocated patients 1:1 to immediate-release oral levodopa/carbidopa plus placebo intestinal gel infusion or LCIG infusion plus oral placebo confirmed previous results of higher "off" time reduction (by 4.04 hours) in the 35 patients on LCIG infusions compared to the 31 patients on oral levodopa therapy (decrease by 2.14 hours). Accordingly, mean "on" time without troublesome dyskinesias showed a higher increase in the LCIG infusion group. Adverse events were very similar in both groups and were mainly associated with the percutaneous gastrojejunostomy tube. Summarized, the results demonstrated the benefit of LCIG infusions for the first time in a (short duration) double-blind controlled study. ${ }^{50}$

\section{Treatment of other motor and nonmotor symptoms}

In addition to the obvious indication for treatment of severely fluctuating patients, decisions on a case-by-case basis have included patients with special forms of dyskinesia ${ }^{51}$ and also 24-hour LCIG administration for better control of nighttime "off" symptoms, with good effects on PD-related sleeping problems. ${ }^{52,53}$ Positive effects of LCIG infusions were also reported in a group of 13 patients with PD who showed not only an amelioration of "off" periods (from a mean of 50\% of awake time at conventional oral pharmacotherapy to a mean of $11 \%$ ) and disabling dyskinesias (from $115 \%$ to $3 \%$ ) but also an improvement of nonmotor symptoms such as anxiety and sleep disturbances. ${ }^{54}$ Honig et al found an amelioration of sleep and further nonmotor symptoms assessed by the Parkinson's disease sleep scale and the nonmotor symptom scale (NMSS). ${ }^{55,56}$ Of the 22 patients with advanced PD who were followed-up 6 months after initiation of LCIG infusion therapy, $95.5 \%$ featured an amelioration of the NMSS total scores, with the most significant improvements seen in urinary and gastrointestinal symptoms, fatigue, attention, and memory. Quality of sleep also improved significantly, however, with different therapeutic regimens for nocturnal symptoms (long-acting dopamine agonists, controlledrelease levodopa, or maintenance of LCIG infusions at night). Improvements in quality of life were highly correlated to changes of the NMSS. ${ }^{56}$

Another open-label study evaluated retrospectively the effects of LCIG infusions on motor and nonmotor symptoms in a group of 14 PD patients, with additional focus on patients and caregivers quality of life. Statistically significant beneficial effects were seen for motor complications while the overall severity of motor impairment did not change over time (patients were followed for an average period of 24.9 months). Interestingly, significant improvements were documented for daytime sleepiness, depressive and psychiatric symptoms, probably caused by dopamine agonists, of which could be ceased under LCIG therapy. According to this investigation, caregivers' stress was not significantly improved, however, the subgroup of patients with improvement of overall condition and functionality also gained improvement of quality of life. ${ }^{57}$

Zibetti et al confirmed previous findings of reduced motor complications and an amelioration of quality of life in an observational study on 25 PD patients with LCIG infusions. However, of 17 subjects who continued LCIG therapy over a follow-up period of 3 years, a subgroup of seven patients developed a significant deterioration of cognitive function over time.$^{58}$ Similar findings were documented by another group with confirmation of long-term beneficial effects of LCIG infusions on motor symptoms, however, with cognitive decline in a subgroup of patients as an indication of disease progression. ${ }^{59}$

\section{Specific adverse events of LCIG}

Pharmacological adverse events related to LCIG infusions have been estimated to be similar to those of conventional oral levodopa therapy. ${ }^{42,60}$ Specific problems are obviously linked to the technical issues of LCIG therapy, especially dislocation of the duodenal tube and other technical problems with the infusion system, which have been reported to occur in about $19 \%$ to $69 \%$ of patients. ${ }^{42,48,61}$ Another risk associated with the PEG procedure is peritonitis, which demands immediate diagnosis and management to prevent life-threatening sequelae, as reviewed by Taheri et al. ${ }^{62}$ Peritonitis has been found to occur in up to $2.3 \%$ of PEGs in a meta-analysis of publications including a very heterogeneous collective of patients. ${ }^{63}$ In PD patients receiving LCIG infusions, there are only single reports on peritonitis, most of them nonfatal and with the majority of affected patients continuing therapy after recovery. ${ }^{48,64}$

In addition to system-related technical side effects, several severe cases of neuropathy have been reported under LCIG therapy, for which mechanisms are still poorly understood. Some of these incidents resembled immune-related forms of neuropathy such as Guillain-Barré syndrome and therefore could be coincidence rather than related to a generic neuropathogenic effect of LCIG. In a recent publication, 
polyneuropathy was observed in four patients of a group of 24 subjects under LCIG treatment. ${ }^{59}$ Klostermann et al reported on two PD patients in a cohort of 20 subjects under LCIG treatment who developed a subacute debilitating axonal neuropathy, which was found to be associated with deficient folate, pyridoxine, and cobalamin levels, with malnutrition as most probable cause. ${ }^{65} \mathrm{In}$ another case series on five patients under LCIG therapy, axonal polyneuropathy had been related to vitamin B12 deficiency. ${ }^{66}$ It has been suggested that neuropathy could be linked to the use of high-dose levodopa, promoting high levels of homocysteine or that the direct intestinal infusion of LCIG could hamper the absorption of vitamins, especially B6 and B12. ${ }^{67}$ Jugel et al found more severe neurographic abnormalities (decreased amplitude of compound muscle action potentials) in a group of 15 patients treated with LCIG infusions than in an age-matched group of PD patients under oral medication. Furthermore, there were correlations between weight loss and the levodopa dosage which were more pronounced in the LCIG group. ${ }^{68}$ Other case series supported a relationship between levodopa and neuropathy, presumably linked to a relative deficiency of vitamin B12 or an imbalance in vitamin B12 and homocysteine, which was thought to be responsible, at least, for the subacute to chronic form of axonal degeneration developing over several weeks to months. ${ }^{69,70}$ More acute, Guillain-Barré-like phenotypes were assumed to reflect inflammatory damage, maybe triggered by vitamin deficiency or other, still not established factors. ${ }^{69}$

Another severe incident has been reported in a patient with therapy-refractory epileptic seizures that have been linked to vitamin B6 deficiency suspected to be caused by malabsorption promoted by high-dose levodopa administration. ${ }^{71}$

\section{Clinical considerations and practical issues}

According to clinical experience and the findings described in the previous paragraphs, LCIG infusions have been shown to lead to a significant amelioration of motor fluctuations and also of certain nonmotor dopaminergic features in advanced PD. However, there are alternative treatment options for a similar collective of PD patients, namely continuous subcutaneous apomorphine treatment and DBS, and one has to keep in mind that there are no studies with an appropriate number of patients directly comparing LCIG infusions with those alternative treatments. In one single investigation, LCIG therapy has been found to be superior to continuous apomorphine (combined with oral levodopa) therapy regarding improvement of motor fluctuations and quality of life in four patients with advanced PD. ${ }^{72}$ In a recent retrospective analysis, 20 patients who had received DBS (subthalamic nucleus) were compared to 20 patients under LCIG treatment: significant amelioration of "on" time was observed with both procedures, whereas only the DBS group showed an improvement of dyskinesias; procedure-related complications were found to occur more frequently with LCIG. ${ }^{73}$ Evidence-based conclusions about the factors for predicting the outcome of LCIG therapy are scarce and are mainly based on a statistical analysis of two studies performed by Nyholm et al, ${ }^{38,40}$ with the result that the most important predictive factor was severity of motor symptoms at baseline. ${ }^{74}$ It is also worth mentioning that younger PD patients without psychiatric or cognitive impairment and without major comorbidities are usually evaluated to be good candidates for DBS surgery. This procedure necessarily leads to some selection bias in such a way that older, multimorbid and/or cognitively impaired patients are more likely to be treated with LCIG therapy. Nonetheless, patients should be cognitively intact enough to manage the handling of the LCIG pump system and should not be severely affected by psychosis or other psychiatric symptoms. ${ }^{27}$

In the clinical setting, the neurologist has to inform and counsel the individual patient of the therapeutic options in the advance stages of PD, taking into account a variety of the patients' characteristics. The unquestionable advantage of LCIG therapy is that it is based on levodopa monotherapy as the most effective drug with little risk of severe pharmacological adverse reactions. Furthermore, it is reversible, and the effects are individually testable without immediate surgical procedure. On the other hand, technical problems and - less frequently - adverse events related to the (minor) surgical PEG procedure are not uncommon, and the patient needs to carry a large device and is dependent on technical support and often continuous support by caregivers to handle the pump. ${ }^{27}$ In the discussion with patients about the pros and cons of LCIG therapy, it is reasonable to explain that the results of the noninvasive nasoduodenal testing period are able to predict the long-term response to therapy, which is the basis for the decision of whether permanent treatment should be initiated.

\section{Conclusion}

According to the existing data and clinical experience, LCIG infusion therapy is a treatment option for patients with PD and motor fluctuations and/or troublesome dyskinesias and/ or severe adverse events under dopamine agonist therapy which demand levodopa monotherapy. LCIG treatment is able to ameliorate "on" time and dyskinesias and has also 
been shown to improve several nonmotor symptoms and sleep disturbance. On the other hand, adverse events under LCIG therapy occur frequently and are mostly related to the gastrointestinal tube and technical issues with the pump system. The possible occurrence of neuropathies must be kept in mind and monitored carefully in the course of treatment.

Another issue is that the successful implementation and long-term treatment with LCIG often requires continuous support by caregivers to deal with the pump, and access to physicians experienced with this kind of therapy has to be assured in case of acute problems or complications.

Although it has been found that severely affected PD patients with dementia (who for example are excluded from surgical therapies) also respond to LCIG treatment, ${ }^{75}$ possible amelioration of motor function has to be carefully weighed against overall functional improvement since LCIG therapy is resource-intensive and expensive. ${ }^{27,76}$ On the other hand, patients' overall estimation of LCIG has been shown to be rather positive, as highlighted in a report by Pickut et al. ${ }^{77}$

Summarized, LCIG infusion therapy is a very promising treatment option for patients in the advanced stages of PD and can be seen as an alternative to DBS, but it is also costly and subject to potential side effects. Therefore, implementation, management, and monitoring require specialized movement disorder centers with support from experienced gastroenterologists. Furthermore, comparative studies are warranted to answer the question of which therapy (conventional oral pharmacotherapy, LCIG, apomorphine, DBS) is best for which subpopulation of PD patients.

\section{Disclosure}

S Skodda received speakers honoraria and travel grants from AbbVie GmbH, Desitin Arzneimittel GmbH, Orion Pharma GmBH, Teva Pharmaceutical Industries LTD, UCB Pharma Ltd, and GlaxoSmithKline plc. The author reports no other conflicts of interest in this work.

\section{References}

1. Hauser RA. Levodopa: past, present, and future. Eur Neurol. 2009;62(1): $1-8$.

2. Merello M, Nouzeilles MI, Arce GP, Leiguarda R. Accuracy of acute levodopa challenge for clinical prediction of sustained long-term levodopa response as a major criterion for idiopathic Parkinson's disease diagnosis. Mov Disord. 2002;17(4):795-798.

3. Hughes AJ, Daniel SE, Kilford L, Lees AJ. Accuracy of clinical diagnosis of idiopathic Parkinson's disease: a clinico-pathological study of 100 cases. J Neurol Neurosurg Psychiatry. 1992;55(3):181-184.

4. Rinne UK. Problems associated with long-term levodopa treatment of Parkinson's disease. Acta Neurol Scand Suppl. 1983;95:19-26.

5. Markham CH, Diamond SG. Long term follow up of early dopa treatment in Parkinson's disease. Ann Neurol. 1986;19(4):365-372.
6. Jankovic J. Motor fluctuations and dyskinesias in Parkinson's disease: clinical manifestations. Mov Disord. 2005;20(Suppl 11):S11-S16.

7. Politis M, Wu K, Molloy S, G Bain P, Chaudhuri KR, Piccini P. Parkinson's disease symptoms: the patient's perspective. Mov Disord. 2010;25(11):1646-1651.

8. Chapuis S, Ouchchane L, Metz O, Gerbaud L, Durif F. Impact of the motor complications of Parkinson's disease on the quality of life. Mov Disord. 2005;20(2):224-230.

9. Bayulkem K, Lopez G. Nonmotor fluctuations in Parkinson's disease: clinical spectrum and classification. J Neurol Sci. 2010;289(1-2):89-92.

10. Olanow CW, Obeso JA, Stocchi F. Continuous dopamine-receptor treatment of Parkinson's disease: scientific rationale and clinical implications. Lancet Neurol. 2006;5(8):677-687.

11. Hauser RA, McDermott MP, Messing S. Factors associated with development of motor fluctuations and dyskinesias in Parkinson's disease. Arch Neurol. 2006;63(12):1756-1760.

12. Chase TN. The significance of continuous dopaminergic stimulation in the treatment of Parkinson's disease. Drugs. 1998;55(Suppl 1):1-9.

13. Nyholm D. The rationale for continuous dopaminergic stimulation in advanced Parkinson's disease. Parkinsonism Relat Disord. 2007; 13(Suppl 1):13-17.

14. Antonini A, Tolosa E. Apomorphine and levodopa infusion therapies for advanced Parkinson's disease: selection criteria and patient management. Expert Rev Neurother. 2009;9(6):859-867.

15. Nutt JG, Woodward WR, Hammerstad JP, Carter JH, Anderson JL. The "on-off" phenomenon in Parkinson's disease. Relation to levodopa absorption and transport. N Engl J Med. 1984;310(8):483-488.

16. Poewe WH, Deuschl G, Gordin A, Kultalahti ER, Leinonen M; Celomen Study Group. Efficacy and safety of entacapone in Parkinson's disease patients with suboptimal levodopa response: a 6-month randomized placebo-controlled double-blind study in Germany and Austria (Celomen study). Acta Neurol Scand. 2002;105(4):245-255.

17. Holloway RG, Shoulson I, Fahn S, et al; Parkinson Study Group. Pramipexole vs levodopa as initial treatment for Parkinson disease: a 4-year randomized controlled trial. Arch Neurol. 2004;61(7): 1044-1053.

18. Rascol O, Brooks DJ, Korczyn AD, et al; 056 Study Group. Development of dyskinesias in a 5-year trial of ropinirole and L-dopa. Mov Disord. 2006;21(11):1844-1850.

19. Critchley PH, Grandas Perez F, Quinn NP, Parkes JD, Marsden CD. Continuous subcutaneous lisuride infusions in Parkinson's disease. J Neural Transm Suppl. 1988;27:55-60.

20. Vaamonde J, Luquin MR, Obeso JA. Subcutaneous lisuride infusion in Parkinson's disease. Response to chronic administration in 34 patients. Brain. 1991;114(Pt 1B):601-617.

21. Manson AJ, Turner K, Lees AJ. Apomorphine monotherapy in the treatment of refractory motor complications of Parkinson's disease: long-term follow-up study of 64 patients. Mov Disord. 2002;17(6): 1235-1241.

22. Antonini A, Odin P. Pros and cons of apomorphine and L-dopa continuous infusion in advanced Parkinson's disease. Parkinsonism Relat Disord. 2009;15(Suppl 4):S97-S100.

23. García Ruiz PJ, Sesar Ignacio A, Ares Pensado B, et al. Efficacy of long-term continuous subcutaneous apomorphine infusion in advanced Parkinson's disease with motor fluctuations: a multicenter study. Mov Disord. 2008;23(8):1130-1136.

24. Deleu D, Hanssens Y, Northway MG. Subcutaneous apomorphine: an evidence-based review of its use in Parkinson's disease. Drugs Aging. 2004;21(11):687-709.

25. Hardie RJ, Lees AJ, Stern GM. On-off fluctuations in Parkinson's disease. A clinical and neuropharmacological study. Brain. 1984; 107(Pt 2):487-506.

26. Mouradian MM, Juncos JL, Fabbrini G, Chase TN. Motor fluctuations in Parkinson's disease: pathogenetic and therapeutic studies. Ann Neurol. 1987;22(4):475-479.

27. Lundqvist C. Continuous levodopa for advanced Parkinson's disease. Neuropsychiatr Dis Treat. 2007;3(3):335-348. 
28. Papathanou M, van der Laan R, Jenner R, et al. Pulsatile and continuous infusions of L-dopa induce abnormal involuntary movements in 6-OHDA-lesioned rats. Poster presented at: Movement Disorder Society 14th Annual International Congress of Parkinson's Disease and Movement Disorders; June 13-17, 2010; Buenos Aires.

29. Bredberg E, Lennernäs H, Paalzow L. Pharmacokinetics of levodopa and carbidopa in rats following different routes of administration. Pharm Res. 1994;11(4):549-555.

30. Kurlan R, Nutt JG, Woodward WR, et al. Duodenal and gastric delivery of levodopa in parkinsonism. Ann Neurol. 1988;23(6):589-595.

31. Kurlan R, Rubin AJ, Miller C, Rivera-Calimlim L, Clarke A, Shoulson I. Duodenal delivery of levodopa for on-off fluctuations in parkinsonism: preliminary observations. Ann Neurol. 1986;20(2):262-265.

32. Sage JI, Schuh L, Heikkila RE, Duvoisin RC. Continuous duodenal infusions of levodopa: plasma concentrations and motor fluctuations in Parkinson's disease. Clin Neuropharmacol. 1988;11(1):36-44.

33. Ruggieri S, Stocchi F, Carta A, Catarci M, Agnoli A. Jejunal delivery of levodopa methyl ester. Lancet. 1989;2(8653):45-46.

34. Bredberg E, Nilsson D, Johansson $\mathrm{K}$, et al. Intraduodenal infusion of a water-based levodopa dispersion for optimisation of the therapeutic effect in severe Parkinson's disease. Eur J Clin Pharmacol. 1993;45(2):117-122

35. Kurth MC, Tetrud JW, Tanner CM, et al. Double-blind, placebocontrolled, crossover study of duodenal infusion of levodopa/carbidopa in Parkinson's disease patients with 'on-off' fluctuations. Neurology. 1993;43(9):1698-1703.

36. Nilsson D, Hansson LE, Johansson K, Nyström C, Paalzow L, Aquilonius SM. Long-term intraduodenal infusion of a water based levodopa-carbidopa dispersion in very advanced Parkinson's disease. Acta Neurol Scand. 1998;97(3):175-183.

37. Stocchi F, Vacca L, Ruggieri S, Olanow CW. Intermittent vs continuous levodopa administration in patients with advanced Parkinson disease: a clinical and pharmacokinetic study. Arch Neurol. 2005;62(6) 905-910.

38. Nyholm D, Askmark H, Gomes-Trolin C, et al. Optimizing levodopa pharmacokinetics: intestinal infusion versus oral sustained-release tablets. Clin Neuropharmacol. 2003;26(3):156-163.

39. Nyholm D, Odin P, Johansson A, et al. Pharmacokinetics of levodopa, carbidopa, and 3-O-methyldopa following 16-hour jejunal infusion of levodopa-carbidopa intestinal gel in advanced Parkinson's disease patients. AAPS J. 2013;15(2):316-323.

40. Nyholm D, Nilsson Remahl AI, Dizdar N, et al. Duodenal levodopa infusion monotherapy vs oral polypharmacy in advanced Parkinson disease. Neurology. 2005;64(2):216-223.

41. Nilsson D, Nyholm D, Aquilonius SM. Duodenal levodopa infusion in Parkinson's disease - long-term experience. Acta Neurol Scand. 2001;104(6):343-348.

42. Nyholm D, Lewander T, Johansson A, Lewitt PA, Lundqvist C, Aquilonius SM. Enteral levodopa/carbidopa infusion in advanced Parkinson disease: long-term exposure. Clin Neuropharmacol. 2008;31(2): 63-73.

43. Antonini A, Isaias IU, Canesi M, et al. Duodenal levodopa infusion for advanced Parkinson's disease: 12-month treatment outcome. Mov Disord. 2007;22(8):1145-1149.

44. Antonini A, Mancini F, Canesi M, et al. Duodenal levodopa infusion improves quality of life in advanced Parkinson's disease. Neurodegener Dis. 2008;5(3-4):244-246.

45. Puente V, De Fabregues O, Oliveras C, et al. Eighteen month study of continuous intraduodenal levodopa infusion in patients with advanced Parkinson's disease: impact on control of fluctuations and quality of life. Parkinsonism Relat Disord. 2010;16(3):218-221.

46. Pålhagen SE, Dizdar N, Hauge T, et al. Interim analysis of long-term intraduodenal levodopa infusion in advanced Parkinson disease. Acta Neurol Scand. 2012;126(6):e29-e33.

47. Foltynie T, Magee C, James C, Webster GJ, Lees AJ, Limousin P. Impact of duodopa on quality of life in advanced Parkinson's disease: a UK case series. Parkinsons Dis.2013:362908.
48. Devos D; French DUODOPA Study Group. Patient profile, indications, efficacy and safety of duodenal levodopa infusion in advanced Parkinson's disease. Mov Disord. 2009;24(7):993-1000.

49. Fernandez HH, Vanagunas A, Odin P, et al. Levodopa-carbidopa intestinal gel in advanced Parkinson's disease open-label study: interim results. Parkinsonism Relat Disord. 2013;19(3):339-345.

50. Olanow CW, Kieburtz K, Odin P, et al; LCIG Horizon Study Group. Continuous intrajejunal infusion of levodopa-carbidopa intestinal gel for patients with advanced Parkinson's disease: a randomised, controlled, double-blind, double-dummy study. Lancet Neurol. 2014;13(2): 141-149.

51. Sage JI, McHale DM, Sonsalla P, Vitagliano D, Heikkila RE. Continuous levodopa infusions to treat complex dystonia in Parkinson's disease. Neurology. 1989;39(7):888-891.

52. Sage JI, Mark MH. Nighttime levodopa infusions to treat motor fluctuations in advanced Parkinson's disease: preliminary observations. Ann Neurol. 1991;30(4):616-617.

53. Nyholm D, Jansson R, Willows T, Remahl IN. Long-term 24-hour duodenal infusion of levodopa: outcome and dose requirements. Neurology. 2005;65(9):1506-1507.

54. Eggert K, Schrader C, Hahn M, et al. Continuous jejunal levodopa infusion in patients with advanced Parkinson disease: practical aspects and outcome of motor and non-motor complications. Clin Neuropharmacol. 2008;31(3):151-166.

55. Chaudhuri KR, Martinez-Martin P, Brown RG, et al. The metric properties of a novel non-motor symptoms scale for Parkinson's disease: Results from an international pilot study. Mov Disord. 2007;22(13):1901-1911.

56. Honig H, Antonini A, Martinez-Martin P, et al. Intrajejunal levodopa infusion in Parkinson's disease: a pilot multicenter study of effects on nonmotor symptoms and quality of life. Mov Disord. 2009;24(10): $1468-1474$.

57. Fasano A, Ricciardi L, Lena F, Bentivoglio AR, Modugno N. Intrajejunal levodopa infusion in advanced Parkinson's disease: long-term effects on motor and non-motor symptoms and impact on patient's and caregiver's quality of life. Eur Rev Med Pharmacol Sci. 2012;16(1):79-89.

58. Zibetti M, Merola A, Ricchi V, et al. Long-term duodenal levodopa infusion in Parkinson's disease: a 3-year motor and cognitive follow-up study. J Neurol. 2013;260(1):105-114.

59. Cáceres-Redondo MT, Carrillo F, Lama MJ, et al. Long-term levodopa/ carbidopa intestinal gel in advanced Parkinson's disease. J Neurol. 2014;261(3):561-569.

60. Fernandez HH, Odin P. Levodopa-carbidopa intestinal gel for treatment of advanced Parkinson's disease. Curr Med Res Opin. 2011;27(5):907-919.

61. Clarke CE, Worth P, Grosset D, Stewart D. Systematic review of apomorphine infusion, levodopa infusion and deep brain stimulation in advanced Parkinson's disease. Parkinsonism Relat Disord. 2009;15(10): 728-741.

62. Taheri MR, Singh H, Duerksen DR. Peritonitis after gastrostomy tube replacement: a case series and review of literature. JPEN J Parenter Enteral Nutr. 2011;35(1):56-60.

63. Potack JZ, Chokhavatia S. Complications of and controversies associated with percutaneous endoscopic gastrostomy: report of a case and literature review. Medscape J Med. 2008;10(6):142.

64. Karlsborg M, Korbo L, Regeur L, Glad A. Duodopa pump treatment in patients with advanced Parkinson's disease. Dan Med Bull. 2010;57(6):A4155.

65. Klostermann F, Jugel C, Müller T, Marzinzik F. Malnutritional neuropathy under intestinal levodopa infusion. J Neural Transm. 2012;119(3): 369-372.

66. Santos-García D, de la Fuente-Fernández R, Valldeoriola F, et al Polyneuropathy while on duodenal levodopa infusion in Parkinson's disease patients: we must be alert. J Neurol. 2012;259(8):1668-1672.

67. Müller T, van Laar T, Cornblath DR, et al. Peripheral neuropathy in Parkinson's disease: levodopa exposure and implications for duodenal delivery. Parkinsonism Relat Disord. 2013;19(5):501-507; discussion 501. 
68. Jugel C, Ehlen F, Taskin B, Marzinzik F, Müller T, Klostermann F. Neuropathy in Parkinson's disease patients with intestinal levodopa infusion versus oral drugs. PLoS One. 2013;8(6):e66639.

69. Mancini F, Comi C, Oggioni GD, et al. Prevalence and features of peripheral neuropathy in Parkinson's disease patients under different therapeutic regimens. Parkinsonism Relat Disord. 2014;20(1):27-31.

70. Merola A, Zibetti M, Rizzone MG, et al. Prospective assessment of peripheral neuropathy in Duodopa-treated parkinsonian patients. Acta Neurol Scand. 2014;129(1):e1-e5.

71. Skodda S, Müller T. Refractory epileptic seizures due to vitamin B6 deficiency in a patient with Parkinson's disease under duodopa ${ }^{\circledR}$ therapy. J Neural Transm. 2013;120(2):315-318.

72. Nyholm D, Constantinescu R, Holmberg B, Dizdar N, Askmark H. Comparison of apomorphine and levodopa infusions in four patients with Parkinson's disease with symptom fluctuations. Acta Neurol Scand. 2009;119(5):345-348.

73. Merola A, Zibetti M, Angrisano S, Rizzi L, Lanotte M, Lopiano L. Comparison of subthalamic nucleus deep brain stimulation and Duodopa in the treatment of advanced Parkinson's disease. Mov Disord. 2011;26(4):664-670.
74. Westin J, Nyholm D, Groth T, Dougherty MS, Yerramsetty PK, Palhagen SE. Outcome prediction of enteral levodopa/carbidopa infusion in advanced Parkinson's disease. Parkinsonism Relat Disord. 2006;12(8):509-513.

75. Annic A, Devos D, Seguy D, Dujardin K, Destée A, Defebvre L. [Continuous dopaminergic stimulation by Duodopa in advanced Parkinson's disease: efficacy and safety]. Rev Neurol (Paris). 2009;165(8-9):718-727. French.

76. Pedersen SW, Clausen J, Gregerslund MM. Practical guidance on how to handle levodopa/carbidopa intestinal gel therapy of advanced PD in a movement disorder clinic. Open Neurol J. 2012;6:37-50.

77. Pickut BA, van der Linden C, Dethy S, Van De Maele H, de Beyl DZ. Intestinal levodopa infusion: the Belgian experience. Neurol Sci. Epub December 31, 2013
Journal of Parkinsonism \& Restless Legs Syndrome

\section{Publish your work in this journal}

Journal of Parkinsonism and Restless Legs Syndrome is an online, open access, peer-reviewed journal. The journal publishes review articles, historical reviews, original research articles, case reports, letters to the editor, clinical teaching cases, neuroradiology highlights, neuropathology highlights, neuropsychiatry highlights, autobiographies, conference

\section{Dovepress}

proceedings, abstracts and book reviews. The manuscript management system is completely online and includes a very quick and fair peerreview system, which is all easy to use. Visit http://www.dovepress.com testimonials.php to read real quotes from published authors. 